\title{
Qualitative analysis of unilateral spatial neglect in relation to laterality of cerebral lesions
}

\author{
G. GAINOTTI, P. MESSERLI, AND R. TISSOT \\ From the Clinic for Nervous and Mental Diseases of the University of Perugia, Italy, \\ and the Neuropsychological Unit of the Clinic of Neurology, University of Geneva, Switzerland
}

SUMMARY Two unselected groups of patients, affected by a mono-hemispheric cerebral lesion, were studied in two separate services by means of various tasks of copying drawings, in order to check the hypothesis of a qualitative difference between unilateral spatial neglect (USN) of right and left brain-damaged patients. In both experimental groups drawing asymmetries were found to be of slight importance among the left hemispheric patients, consisting chiefly in a tendency to omit some figures lying on the right half of the models, and to be definitely more severe in the right braindamaged patients, where the main pattern of USN seemed to be the tendency to leave unfinished the left half of the drawings. A second aim of the study was to describe some less frequent features of USN, sometimes found in patients who were recovering from a severe damage of the minor hemisphere. These patterns of USN seemed to suggest that the core of unilateral spatial neglect consists in a peculiar disorganization of the type of synthesis of the sensory data which seems characteristic of the minor hemisphere.

Of all the various types of 'spatial' disorders described by clinical neurologists none is more frequent and dramatic than the syndrome of unilateral spatial neglect (USN). Initially described by Holmes (1918), Poppelreuter (1923), and Riddoch (1935), and discussed in detail by Brain (1941), this syndrome consists of a tendency to neglect one half of extrapersonal space in such tasks as drawing and reading which require a good and symmetrical exploration of space. Studied in a first period on small groups of patients, USN has been investigated in recent years in a more systematic manner, by comparing the performances of unselected groups of right and left brain-damaged patients, who were submitted to tasks requiring an adequate exploration of space. However, the results of these researches have been at variance, and disagreement still exists about both incidence and qualitative aspects of USN in lateralized cerebral lesions. Battersby, Bender, Pollack, and Kahn (1956) found that lesions of the posterior areas of either hemisphere frequently produced USN, but Hécaen (1962) reported that in his series of 59 patients with USN only one case was suffering from a left hemispheric lesion, and emphasized the relationship between USN and lesions of the minor hemisphere. Gainotti (1968) attempted to study the same problem by means of a battery of tests simple enough to be administered to all patients, including severe aphasics. His results showed that USN is not only significantly more frequent, but also definitely more severe in patients suffering from lesions of the right hemisphere.

These conclusions were only in part confirmed by Costa, Vaughan, Horwitz, and Ritter (1969), who found that the incidence of USN is greater in patients with right hemispheric lesions, but that severity and patterns of deficit are alike in both right and left lesioned groups.

The purpose of the present study has been to check the hypothesis of a qualitative difference between USN of patients with right and left hemispheric lesions, by means of a careful analysis of the severity and of the patterns of USN shown by these patients when submitted to various tasks of copying drawings.

The investigation was carried out on the basis of the findings obtained from the application of the usual tests for constructional apraxia in two separate services: the Clinic for Nervous and Mental Diseases of the University of Perugia, and the Neuropsychological Unit of the Depart- 
ment of Neurology of the University of Geneva.

In both services the data had been collected on large groups of patients chosen not because they showed the symptoms, but because of the presence of a focal lesion. On the other hand, methods of investigation were not homogeneous: in the Perugia clinic drawing disability had been studied by means of a standard battery of copying geometrical designs, while in the Geneva unit constructional apraxia had been investigated by means of a traditional clinical method.

Subjects, procedures, and results obtained in the two services will then be presented separately, and only in the discussion will a synthesis be attempted.

\section{STUDY 1: METHODS}

Two groups of 118 left and 120 right brain-damaged patients were given a test of copying designs. For this task the six models (Fig. 1) used by Arrigoni and De Renzi (1964) were presented, with the instruction to copy the designs 'as exactly as possible' on a sheet of paper of the same size as the model.

Five patterns of error, observed on the half of the drawings opposite to the hemispheric locus of lesion, were taken into account: (1) omission of the small lateral figures in models 5 or 6 ; (2) omission of the large lateral figures in models 5 or 6 ; (3) tendency to $\stackrel{\mathbb{C}}{\frac{\mathrm{C}}{\mathrm{C}}}$ leave unfinished one half of one or more figures;은 (4) neglect of one half of model 3, but reproduction $\underset{\mathbb{}}{Z}$ of a significant fragment (the small lateral square) on the neglected side (Fig. 2); (5) neglect of one half of of the central rhombus in model 6 , but reproduction 6 on the neglected side, of the lateral figure of the design (Fig. 2).

These features of USN may be divided into two groups: patterns (1), (2), and (3) consist of behaviours $\stackrel{7}{\overrightarrow{7}}$ of omission or neglect of one half of the space. commonly described by the authors; patterns (4) $\overrightarrow{\overrightarrow{\vec{B}}}$ and (5), on the contrary, analyse a feature of USN which, to our knowledge, has not yet been reported $\frac{\sigma}{\sigma}$ in neuropsychological literature - that is, the ten-⿳亠丷厂 dency to neglect one half of a figure (on the side $\widehat{\widetilde{\Phi}}$ opposite to the hemispheric locus of lesion), while reproducing designs that are placed even morew laterally on the neglected side.

Sixteen of the 238 patients were excluded from the investigation because their graphic task was limited to scrawling: 10 of the excluded patients had left cerebral lesions and six right-sided lesions. The matched experimental groups were therefore composed of 108 subjects with left hemispheric damage and of 114 patients with right cerebral lesions. Theyju represented all the patients admitted to the Clirnicer for Nervous and Mental Diseases of the Univers $f_{y}$ ? of Perugia during a period of three years (from 1987-

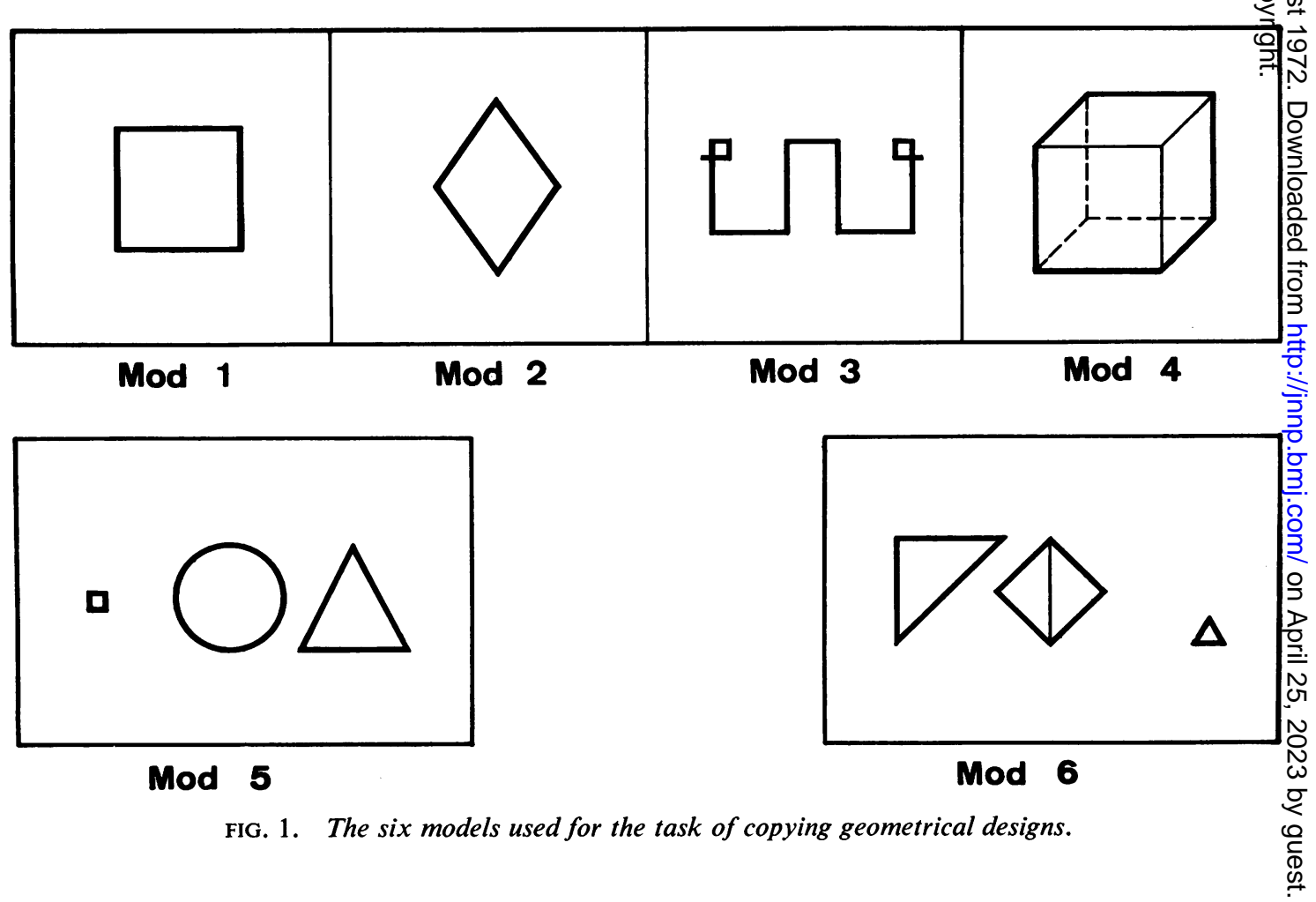


to 1970) for a disease limited to one cerebral hemisphere. No selection had been made in forming the groups, and we took special care to include also the most impaired aphasic patients. All left-handed patients were excluded.

The damaged hemisphere was ascertained from each patient's clinical symptoms and from the results of electroencephalographic, brain-scan, and neuroradiological investigations. No significant differences were found between the two groups with regard to age, educational level, aetiology, and length of illness.

Visual field defects were checked by a simple confrontation test carried out separately in the superior and inferior quadrants, and supplemented in the apparently negative cases by double stimulation. Patients who consistently failed to notice or extinguished the stimulus in a given quadrant were considered as being affected by hemianopsia; there were $\mathbf{4 8}$ hemianopic subjects in the right group, and 33 in the left group $\left(x^{2}=2 \cdot 71 ; P=\right.$ not significant $)$. It should, therefore, be noticed that there was in our research a tendency for the right brain-damaged patients to have a higher incidence of visual field defects, but that this difference did not reach the level of statistical confidence. Magnitude of visual field defect was assessed with the same criteria as described in a previous study of unilateral spatial neglect (Gainotti, 1968). No difference was found between right and left hemispheric patients: 12 subjects in the right group and 12 in the left one showed extinction only in a quadrant, 24 right and 12 left hemispheric patients failed to notice the stimulus in a quadrant, while 12 right and nine left brain-damaged patients showed a complete hemianopsia.

\section{STUDY 1: RESULTS}

Table 1 summarizes the patterns of unilateral spatial neglect (USN) found in right and left brain-damaged patients:

TABLE 1

PATTERNS OF UNILATERAL SPATIAL NEGLECT FOUND IN RIGHT AND LEFT HEMISPHERIC PATIENTS

\begin{tabular}{|c|c|c|c|c|c|}
\hline \multicolumn{2}{|l|}{ Pattern } & \multirow{2}{*}{$\begin{array}{c}\text { Right } \\
32 \\
82\end{array}$} & \multirow{2}{*}{$\begin{array}{c}\text { Left } \\
22 \\
86\end{array}$} & \multirow{2}{*}{$x^{2}$} & \multirow{2}{*}{$\begin{array}{r}P \\
\text { NS }\end{array}$} \\
\hline $\begin{array}{l}\text { 1. Omission of a small } \\
\text { lateral figure }\end{array}$ & $\stackrel{+}{-}$ & & & & \\
\hline $\begin{array}{l}\text { 2. Omission of a large } \\
\text { lateral figure }\end{array}$ & + & $\begin{array}{l}19 \\
95\end{array}$ & $\begin{array}{r}3 \\
105\end{array}$ & 11,974 & 0.005 \\
\hline \multirow[t]{2}{*}{ 3. Unfinished figures } & \pm & $\begin{array}{l}27 \\
87\end{array}$ & 107 & 26,055 & 0.0005 \\
\hline & & & & Right & Left \\
\hline \multicolumn{3}{|c|}{$\begin{array}{l}\text { 4. Neglect for one half of the model } 3 \text {, } \\
\text { but reproduction, on the neglected } \\
\text { side, of the small lateral square }\end{array}$} & \pm & $\begin{array}{r}6 \\
108\end{array}$ & $\begin{array}{r}0 \\
108\end{array}$ \\
\hline \multicolumn{3}{|c|}{$\begin{array}{l}\text { 5. Neglect for one half of the central } \\
\text { rhombus in model } 6 \text {, but reproduction } \\
\text { on the same side of the lateral figure }\end{array}$} & \pm & $11 \frac{3}{1}$ & $\begin{array}{r}0 \\
108\end{array}$ \\
\hline
\end{tabular}

Table 1 may be divided into two parts: (1) analysis of the first three patterns; and (2) analysis of the last two types of qualitative features.

The analysis of the first three patterns shows that the difference between the groups of right and left hemispheric patients does not reach the level of statistical significance when the omission of a small lateral figure is taken into account. This difference becomes, on the contrary, remarkable when the omission of a large lateral figure is taken into consideration, and even more important when we consider the tendency to leave unfinished the figures on the side opposite to the hemispheric locus of lesion. The analysis of patterns (4) and (5) shows that the tendency to neglect one half of a figure (on the side opposite to the hemispheric locus of lesion), reproducing, however, designs that are placed even more laterally on the neglected side, may be found only in some right hemispheric patients. Examples of patterns (4) and (5) are presented in Fig. 2.

\section{STUDY 2: METHODS}

The clinical records of about 300 patients who had been examined at the Neuropsychological Laboratory of the Department of Neurology of the University of Geneva were considered: 191 of these

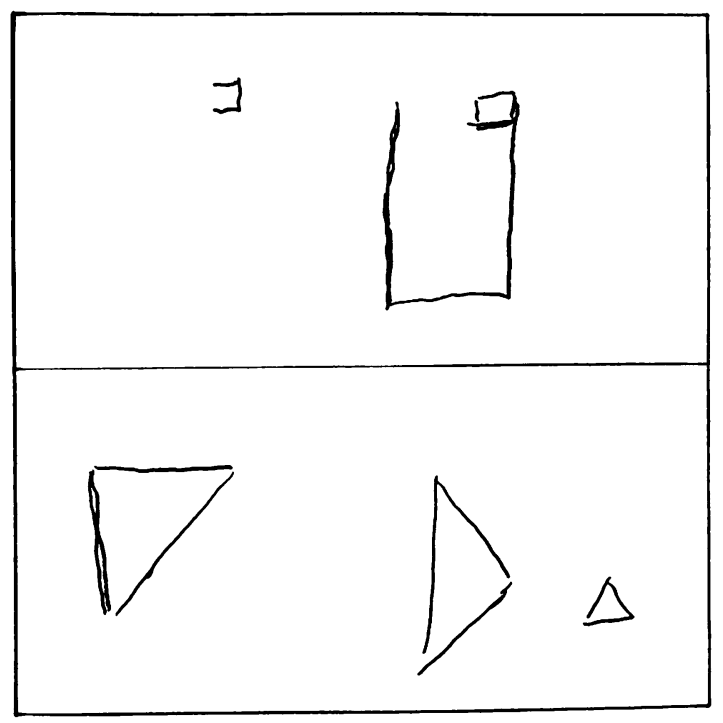

FIG. 2. Examples of the patterns (4) and (5) of unilateral spatial neglect. 
subjects showed evidence of a cerebral lesion limited to the posterior part of one hemisphere. All patients with diffuse cerebral damage or with obvious bilateral lesions, all patients presenting evidence of a focal damage limited to the frontal lobe, and all left-handed patients were excluded. No other selection was made in forming the groups, and we took special care to include also the most impaired aphasic patients.

One hundred and twelve of the 191 subjects retained for the present investigation had left-sided lesions, and 79 had right hemispheric damage. No significant differences were found between the two groups with regard to age, social-cultural level, and aetiology of illness, but the two groups were not homogeneous in relation to assessment procedures, since research of constructional apraxia and of USN had been generally more careful in right hemispheric patients. However, some tasks of copying drawings of a house and of a cube had been given in a standard manner to all patients. We then matched the two hemispheric groups in relation to the qualitative features of USN which could be found in the drawings of the house and of the cube.

Two patterns of error (observed on the half of the designs opposite to the hemispheric locus of lesion) were taken into account: (A) tendency to leave unfinished one half of the house or of the cube; (B) tendency to close the figures in a rough and undifferentiated way.

Furthermore, most of the right $(\mathrm{N}=52)$ and some of the left $(\mathrm{N}=26)$ brain-damaged patients had copied a complex model (Fig. 3), consisting of many elements (a house, some trees, a wooden fence, etc.) ranging in a line from left to right. Two patterns of USN were studied within this group of patients: (C) omission, on the side opposite to the hemispheric locus of lesion, of at least one of the elements of the model, without any other sign of unilateral spatial agnosia; (D) tendency to leave unfinished, on the neglected side, the half of one or more elements, reproducing, at the same time, other parts of the model, which are placed even more laterally on the neglected half of space.

\section{RESULTS}

The patterns of USN shown by right and left brain-damaged patients are reported in Table 2 . Data obtained in this group of patients are in agreement with the qualitative features of USN observed in the first sample of subjects on the following points:

i. Drawing asymmetry is of slight importance in the left brain-damaged patients, and consists of a severe neglect in right lesioned subjects.

ii. The main pattern of USN seems to be that in both groups of right hemispheric patients the tendency is to leave unfinished the left half of the drawings (patterns 3 of Table 1 and $A$ of Table 2).

iii. Among the left brain-damaged patients, unilateral spatial inattention consists chiefly in the tendency to omit the designs lying on the right half of the model (patterns 1 of Table 1 and $\mathrm{C}$ of Table 2).

TABLE 2

QUALITATIVE FEATURES OF USN FOUND IN PATIENTS WITH RIGHT-SIDED AND LEFT-SIDED HEMISPHERIC LESIONS

\begin{tabular}{|c|c|c|c|c|c|}
\hline Qualitative features & & $\begin{array}{c}\text { Right } \\
(N=79)\end{array}$ & $\begin{array}{c}\text { Left } \\
(N=112)\end{array}$ & $x^{2}$ & $P$ \\
\hline $\begin{array}{l}\text { A. Unfinished half of } \\
\text { the house or of } \\
\text { the cube }\end{array}$ & $\stackrel{+}{-}$ & $\begin{array}{l}34 \\
45\end{array}$ & $\begin{array}{r}4 \\
108\end{array}$ & 45,263 & 0.0005 \\
\hline $\begin{array}{l}\text { B. Tendency to close } \\
\text { the figures in a } \\
\text { rough and un- } \\
\text { differentiated way }\end{array}$ & $\begin{array}{l}+ \\
-\end{array}$ & $\begin{array}{r}4 \\
75\end{array}$ & $\begin{array}{l}22 \\
90\end{array}$ & 8,364 & $0 \cdot 005$ \\
\hline
\end{tabular}

\begin{tabular}{|c|c|c|c|c|c|c|}
\hline & & & $\begin{array}{c}\text { Right } \\
(N=52)\end{array}$ & $\begin{array}{c}\text { Left } \\
(N=26)\end{array}$ & $x^{2}$ & $P$ \\
\hline C. & $\begin{array}{l}\text { Omission of at } \\
\text { least one of the } \\
\text { elements of the } \\
\text { model }\end{array}$ & $\begin{array}{l}+ \\
-\end{array}$ & $\begin{array}{l}11 \\
41\end{array}$ & $\begin{array}{r}4 \\
22\end{array}$ & 0,362 & NS \\
\hline D. & $\begin{array}{l}\text { Reproduction of } \\
\text { all the elements } \\
\text { but unfinishing } \\
\text { one or more } \\
\text { figures }\end{array}$ & $\begin{array}{l}+ \\
-\end{array}$ & $\begin{array}{l}15 \\
37\end{array}$ & $\begin{array}{r}0 \\
26\end{array}$ & 9,279 & 0.00 \\
\hline
\end{tabular}

iv. Some right brain-damaged patients (and no left one) show the tendency to leave unfinished the half of one or more elements on the side opposite to the hemispheric locus of lesion, $\overline{\vec{a}}$ reproducing, however, other parts of the modelnamely, those placed even more laterally on the neglected half of space (patterns 4 and 5 of Table 1 and D of Table 2).

At the same time, a comparison of data? reported in Tables 1 and 2 shows that the 3 patterns of USN which can be put in evidence 8 are in part a function of the model's own characteristics.

The difficulties in spatial exploration of left brain-damaged patients are, in fact, brought to을. light not only by the omission of the figures (often irrelevant) lying on the right half of the models, but also by the tendency to close $N$ roughly the right half of the designs, when copying the cube or the house. 


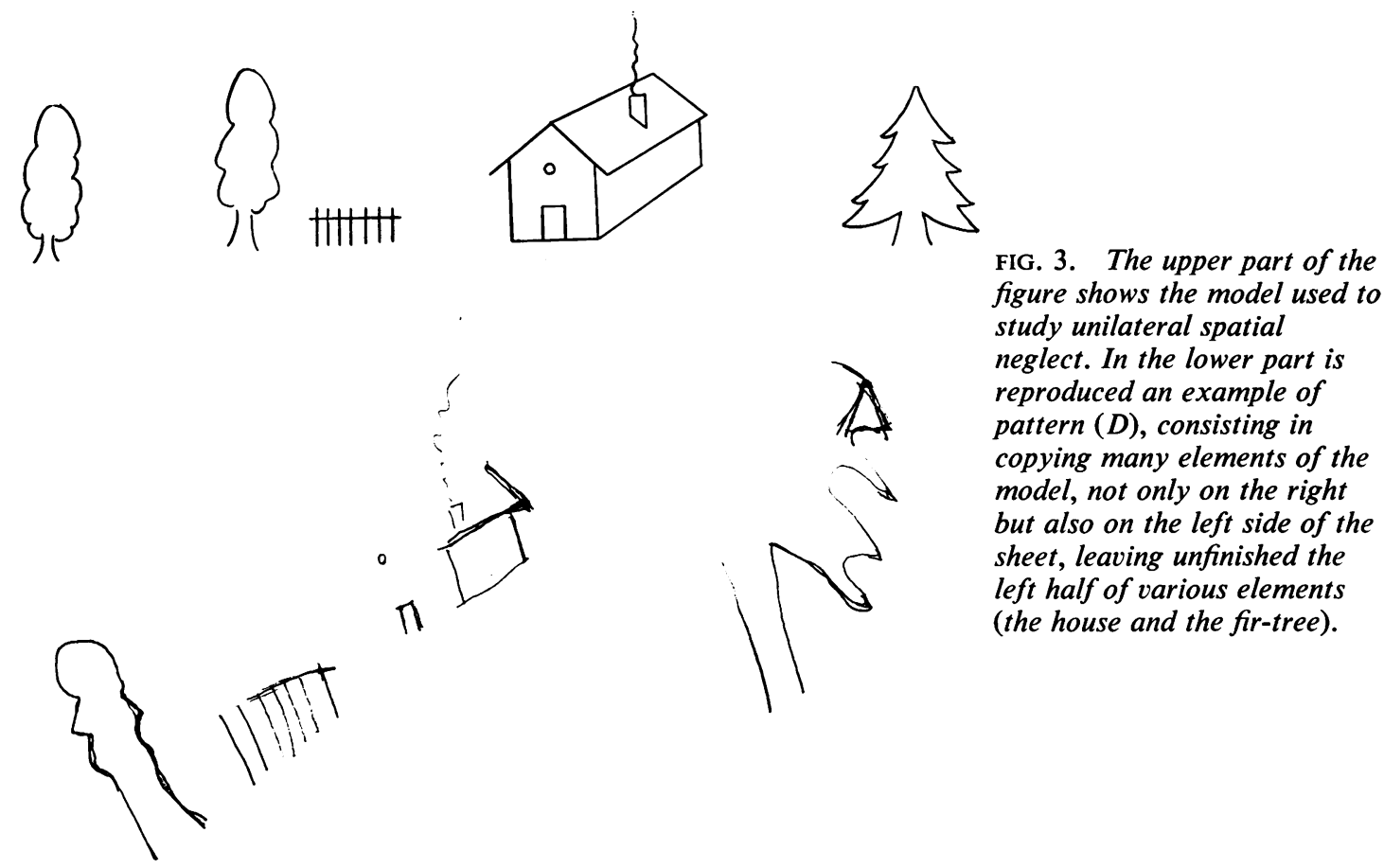

Likewise, patterns 4 and 5 of Table 1 and pattern D of Table 2 show the same phenomenon (the right hemispheric patients with USN do not always limit their visual exploration to the right half of the models, but they often leave unfinished the left half of one or more elements lying on both sides of the paper). However, this phenomenon is hardly recognizable in patterns 4 and 5 of Table 1 (and in Fig. 2) and becomes evident only when we analyse the complex model presented in Fig. 3 (pattern D of Table 2).

\section{DISCUSSION}

In both samples of brain-damaged patients examined in this study, incidence, severity, and qualitative aspects of USN were found to be significantly different according to the hemispheric locus of lesion. These findings are in agreement with the previous results of Gainotti (1968), and give support to his hypothesis that sensory data may have a different functional organization in each hemisphere. Moreover, our results are in accordance with the findings of various authors who have studied constructional apraxia by means of the tasks of copying drawings employed for the two sections of the present investigation. The test of copying geometrical drawings, used in the first part of our inquiry, had already been used by Arrigoni and De Renzi (1964) and by De Renzi and Faglioni (1967). These authors noticed that some qualitative differences exist between the performances of the two hemispheric groups, and have taken into account three features of USN which are analogous to the patterns (1), (2), and (3) of the first part of the present investigation. Their findings, in full agreement with our results, show that the difference between right and left hemispheric patients is not important when the omission of a small lateral figure is taken into consideration, but that it becomes clear when the omission of a large lateral figure or the tendency to leave unfinished one half of the designs is taken into account. Furthermore, Ajuriaguerra and Hécaen (1960), studying constructional apraxia with a clinical method analogous to the procedure employed in the second part of the present investigation, had noticed that, if USN is a symptom characteristic of the right posterior lesions, the left braindamaged patients can also sometimes show some difficulties in copying the right sides of the models. However, in these cases it is not possible to speak of a true USN, since patients, instead of omitting the right half of the designs, overscore 
the lines already drawn on the right side of the figures, in a rough and unsatisfactory way. The likeness between these clinical observations and the quantitative results of the second part of our investigation is evident.

The results of the present investigation and the data of the neuropsychological literature allow us, therefore, to state that USN is a syndrome characteristic of right hemispheric lesions. When similar disturbances are found in left hemispheric patients, they are definitely less severe, and may be considered as due to 'inattention' to what is placed in a section of space which (because of homonymous hemianopia) is out of the actual visual field of the patients. This interpretation seems, on the contrary, insufficient to explain the striking manifestations of neglect evidenced by many right hemispheric patients.

It is interesting to notice that De Renzi, Faglioni, and Scotti (1970) have proved, in a recent paper, that USN is not limited to the visual modality, but that it may appear also in a tactually guided test. This finding has led the authors to advance the hypothesis that USN may not depend so much on perceptual and motor factors as 'on a cognitive deficit which may be viewed as a mutilated representation of space'. Some of the features of USN that we have described in the present investigation (patterns 4 and 5 of Table 1 and pattern D of Table 2) seem, however, to indicate that patients do not have a cognitive defect. These patients are conscious of the existence of the left half of space; their exploratory behaviour is not abolished on that side, but it is the integration of the simultaneous visual inputs that seems to be disturbed in the left half of space. It seems to us, therefore, that the USN observed by De Renzi et al. (1970) in a representative task is not necessarily of a representative nature. This behaviour might reflect also a lack of integration of the left half of extrapersonal space, which could be found as well in sensory-motor and in representative tasks. It is to be noticed, however, that these qualitative features, although not exceptional in the right brain-damaged patients, were never found in the acute periods that immediately followed the strokes. Therefore the hypothesis may be advanced that these behaviours may be considered as unsuccessful attempts to compensate USN, which could be observed when the patients become partially conscious of the symptom.

Further analytical studies of the temporal evolution of unilateral spatial agnosia, and more objective records of the eye movements and of the visual perceptual function are needed in order to verify this hypothesis.

\section{REFERENCES}

Ajuriaguerra, J. de, and Hécaen, H. (1960). Le Cortex Cérébral, 2e édition. Masson: Paris.

Arrigoni, G., and De Renzi, E. (1964). Constructional apraxia and hemispheric locus of lesion. Cortex, 1, 170-197.

Battersby, W. S., Bender, M. B., Pollack, M., and Kahn, R. L. (1956). Unilateral 'spatial agnosia' ('inattention in patients with cerebral lesions. Brain, 79, 68-93.

Brain, W. R. (1941). Visual disorientation with specia reference to lesions of the right cerebral hemisphere Brain, 64, 244-272.

Costa, L. D., Vaughan, H. G., Jr., Horwitz, M., and Ritte $\square$ W. (1969). Patterns of behavioral deficit associated with visual spatial neglect. Cortex, 5, 242-263.

De Renzi, E., and Faglioni, P. (1967). The relationsh between visuo-spatial impairment and construction雪 apraxia. Cortex, 3, 327-342.

De Renzi, E., Faglioni, P., and Scotti, G. (1970). Hemispheric contribution to exploration of space through the visual and tactile modality. Cortex, 6, 191-203.

Gainotti, G. (1968). Les manifestations de négligence et d'inattention pour l'hémispace. Cortex, 4, 64-91.

Hécaen, H. (1962). Clinical symptomatology in right and left hemispheric lesions. In Interhemispheric Relations and $\mathrm{Q}$ Cerebral Dominance, pp. 215-243. Edited by V. B. Mountcastle. Johns Hopkins Press: Baltimore.

Holmes, G. (1918). Disturbances of visual orientation. British Journal of Ophthalmology, 2, 449-468.

Poppelreuter, W. (1923). Zur Psychologie und Pathologie der optischen Wahrnehmung. Zeitschrift für die gesamte Neurologie und Psychiatrie, 83, 26-152.

Riddoch, G. (1935). Visual disorientation in homonymous half-fields. Brain, 58, 376-382. 